\title{
Catanionic Reverse Micelles as an Optimal Microenvironment To Alter the Water Electron Donor Capacity in a $\mathrm{S}_{\mathrm{N}} 2$ Reaction
}

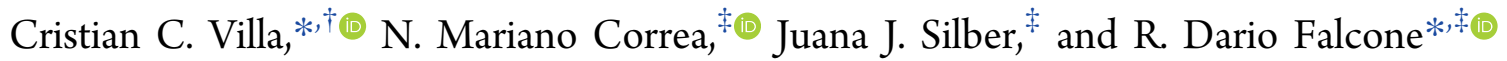 \\ ${ }^{\dagger}$ Programa de Química, Universidad del Quindío, Carrera 15 Calle 14 Norte C.P. 630004 Armenia, Colombia \\ ‡Departamento de Química, Universidad Nacional de Río Cuarto, Agencia Postal \# 3 C.P. X5804BYA Río Cuarto, Argentina
}

\section{Supporting Information}

ABSTRACT: The effect of interfacial water entrapped in two types of catanionic reverse micelles (RMs) on the kinetic parameters of the $S_{N} 2$ reaction between dimethyl-4-nitrophenylsulfonium trifluoromethanesulfonate $\left(\mathrm{S}^{+}\right)$and $n$-butylamine $\left(\mathrm{BuNH}_{2}\right)$ was explored. Two catanionic surfactants, composed of a mixture of oppositely charged ionic surfactants without their original counterions, were used to create the RMs. Thus, benzyl- $n$-hexadecyldimethylammonium 1,4-bis(2-ethylhexyl) sulfosuccinate (BHD-AOT) and cetyltrimethylammonium 1,4-bis(2-ethylhexyl) sulfosuccinate (CTA-AOT) were formed. Also, the wellknown anionic surfactant sodium 1,4-bis(2-ethylhexyl) sulfosuccinate (Na-AOT) was employed as a comparison. Our results showed an important catalytic-like effect of all RMs investigated in comparison with a water-benzene mixture, and the rate constant values depend on the type of surfactant used. Faster reaction in BHD-AOT RMs than in CTA-AOT and Na-AOT RMs was observed. This

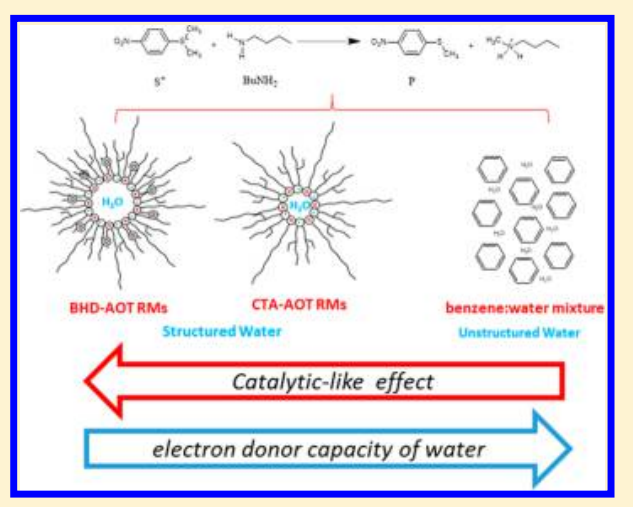
behavior was attributed to the strong interaction (by hydrogen bonding with AOT anion and ion-dipole interaction with $\mathrm{BHD}^{+}$) between the entrapped water and the BHD-AOT interface, which reduces the solvation capacity of water on $\mathrm{S}^{+}$. In CTA-AOT (and Na-AOT) RMs, the water-interface interaction is weaker and the electron pairs of water can solvate $\mathrm{S}^{+}$ions. In summary, the chemical structure of the counterion on the catanionic surfactant alters the interfacial region, allowing the progress of a reaction inside the RMs to be controlled.

\section{INTRODUCTION}

Reverse micelles (RMs) are supramolecular aggregates formed by surfactant molecules dispersed in nonpolar solvents. RMs are organized so that the surfactant head groups point inward to the center containing the polar solvent and the hydrophobic tails extend outward into the organic nonpolar continuous phase, allowing them to encapsulate water or other polar solvents in their polar heart. ${ }^{1,2}$ Taking into account their conformation, RMs have shown a wide array of applications, which include their use as mimetic agents, in cell biomembrane modeling, in drug delivery, in oil recovery enzymology, and as "nanoreactors" for organic molecules and nanoparticles synthesis. $^{3-12}$

It is known that physicochemical properties of the RMs are affected by several parameters such as nonpolar solvent composition, temperature, type of surfactant, and the molar ratio of water (or polar solvent)-to-surfactant. This last parameter, defined as $W_{0}=$ [water $] /[$ surfactant $]$, reflects the polar solvent content within RMs. ${ }^{1,13-18}$ In recent years we have reported the synthesis and characterization of two catanionic surfactants (mixtures of two opposite charged ionic surfactants where the original counterions have been removed), benzyl- $n$-hexadecyldimethylammonium 1,4-bis(2ethylhexyl) sulfosuccinate (BHD-AOT, Scheme 1) and cetyltrimethylammonium 1,4-bis(2-ethylhexyl) sulfosuccinate (CTA-AOT, Scheme 1). ${ }^{19-21}$ These two compounds, which are also ionic liquids (ILs), have shown interesting properties as surfactants to create organized systems. ${ }^{19-22}$ We have demonstrated that these new surfactants form spherical RMs in different nonpolar solvents and that the magnitude of the water-catanionic surfactant interaction at the interface is different in both systems. ${ }^{21}$ In BHD-AOT RMs a strong water-surfactant interaction was detected while for CTA-AOT this interaction seems to be weaker. These results are interesting because a simple change in the cationic component of the catanionic surfactant promotes remarkable changes in the RM interface, particularly in the water-surfactant interaction. For example, BHD-AOT RMs offer a less electron donating environment than CTA-AOT. ${ }^{21}$

The differences in the physicochemical properties of the RMs systems can have a great impact on the kinetic parameters of chemical ${ }^{7,23}$ and enzymatic reactions. ${ }^{9,24-26}$ Nevertheless, to the best our knowledge, the effect of a catanionic interface on the kinetic parameters of a chemical reaction has not yet been assessed. In this work, we studied the kinetics of the reaction between dimethyl-4-nitrophenylsulfonium trifluoromethanesulfonate $\left(\mathrm{S}^{+}\right)$and $n$-butylamine $\left(\mathrm{BuNH}_{2}\right)$ as an $\mathrm{S}_{\mathrm{N}} 2$ model (Scheme 2) to fully understand the microenvironment of the catanionic micellar interface.

Received: September 26, 2018

Published: January 4, 2019 
Scheme 1. Molecular Structures of CTA-AOT and BHDAOT<smiles>CCCCCCCCCCCCCCCC[N+](C)(C)C</smiles>

CTA-AOT<smiles>CCCCCCCCCCCCCCCC[N+](C)(C)Cc1ccccc1</smiles>

BHD-AOT

\section{RESULTS AND DISCUSSION}

To fully understand the effect of the catanionic micellar media on the $S_{N} 2$ reaction, first we studied the behavior of this reaction in homogeneous media and later in different RMs: Na-AOT, BHD-AOT, and CTA-AOT. At this point, it is necessary to denote that the kinetic data in BHDC RMs are not included as a comparison because the counterion chloride of the surfactant acts as a strong nucleophile for the reaction, ${ }^{7}$ competing with $\mathrm{BuNH}_{2}$ for $\mathrm{S}^{+}$.

2.1. Studies in Homogeneous Media. The observed spectra of the mixture of $\mathrm{S}^{+}$with $\mathrm{BuNH}_{2}$ at different times are shown in Figure S1A. In Figure S1B is shown the absorbance changes at $\lambda=342 \mathrm{~nm}$ as a function of time. The reaction of $\mathrm{S}^{+}$ with $\mathrm{BuNH}_{2}$ is a bimolecular reaction, which follows the rate law described in eq S1 and, as mentioned previously that $\left[\mathrm{BuNH}_{2}\right] \gg\left[\mathrm{S}^{+}\right]$, the system presents a typical pseudo-firstorder behavior. Thus, the $k_{\text {obs }}$ values obtained in this media as a function of the [nucleophile] are plotted in Figure 1. The procedure to obtain the $k_{\text {obs }}$ values from the absorbance changes is fully described in Supporting Information.

As observed, there is a linear dependence of $k_{\text {obs }}$ values on the $\mathrm{BuNH}_{2}$ concentration. From the linear fit (eq S2), the second-order rate constant $\left(k_{2}\right)$ value is obtained $((2.2 \pm 0.1)$ $\times 10^{-2} \mathrm{M}^{-1} \mathrm{~s}^{-1}$, Table 1$)$. A similar value in toluene was reported by Ranieri et al. ${ }^{27}$ As our goal was to study the

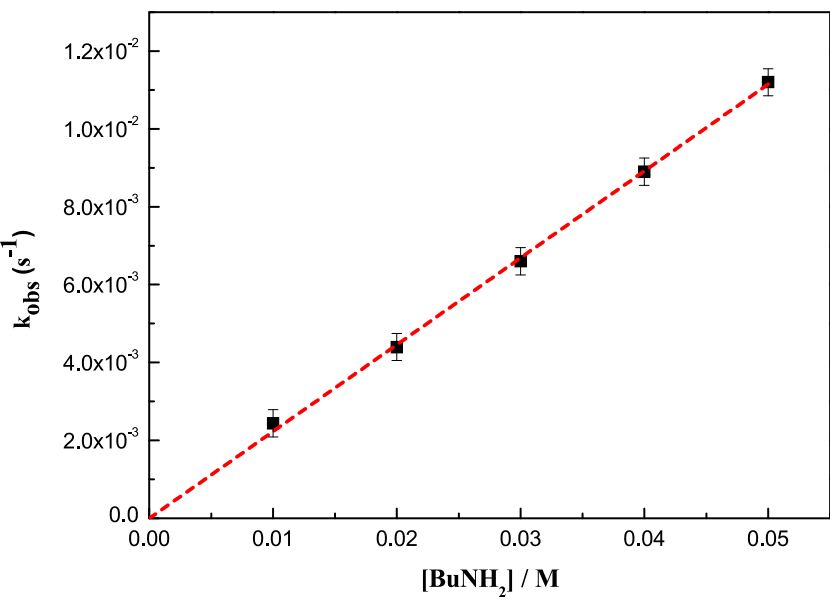

Figure 1. Dependence of $k_{\text {obs }}$ values with the $\mathrm{BuNH}_{2}$ concentration for the reaction between $\mathrm{S}^{+}$and $\mathrm{BuNH}_{2}$ in neat benzene. $\left[\mathrm{S}^{+}\right]=5 \times$ $10^{-5} \mathrm{M} . \mathrm{T}=30^{\circ} \mathrm{C}$.

Table 1. Second-Order Rate Constant Values for the Reaction of $\mathrm{S}^{+}$and $\mathrm{BuNH}_{2}$ in Different Solvents and $\mathrm{RM}$ Media at $30{ }^{\circ} \mathrm{C}^{a}$

\begin{tabular}{lccc}
\multicolumn{1}{c}{ media } & $W_{0}$ & $k_{2}\left(\mathrm{M}^{-1} \mathrm{~s}^{-1}\right)$ & $k_{\mathrm{i}}\left(\mathrm{M}^{-1} \mathrm{~s}^{-1}\right)$ \\
neat benzene & & $(2.2 \pm 0.1) \times 10^{-1}$ & \\
benzene:water & & $(7.8 \pm 1.0) \times 10^{-5}$ & \\
neat water & & no reaction detected \\
Na-AOT & 0 & & $(3.2 \pm 0.1) \times 10^{-3}$ \\
& 1.5 & & $(8.4 \pm 0.2) \times 10^{-4}$ \\
& 10 & & $(1.3 \pm 0.1) \times 10^{-4}$ \\
BHD-AOT & 0 & & $(1.20 \pm 0.02) \times 10^{-2}$ \\
& 1.5 & & $(7.6 \pm 0.1) \times 10^{-3}$ \\
CTA-AOT & 0 & & $(5.8 \pm 0.2) \times 10^{-3}$ \\
& 1.5 & & $(9.6 \pm 0.1) \times 10^{-4}$
\end{tabular}

${ }^{a} k_{2}$ is the second-order rate constant in homogeneous media, and $k_{\mathrm{i}}$ is the second-order rate constant for the reaction in the RMs. $\left[\mathrm{BuNH}_{2}\right]$ $=0.03 \mathrm{M}$.

kinetics of this reaction in RMs systems without $\left(W_{0}=0\right)$ and with water $\left(W_{0}>0\right)$, it was interesting to study the effect of water on the kinetic parameters of this reaction in homogeneous media. Thus, the reaction was investigated in benzene saturated with water, where the water solubility is around $0.03 \mathrm{M}^{28}$ and the $k_{\text {obs }}$ values obtained are plotted in Figure S2. As shown, there is also a linear dependence of $k_{\mathrm{obs}}$ on $\mathrm{BuNH}_{2}$ concentration in benzene saturated by water. The $k_{2}$ value calculated for benzene saturated with water is $(7.8 \pm$ 1.0) $\times 10^{-5} \mathrm{M}^{-1} \mathrm{~s}^{-1}$, and it is three-fold smaller than in neat benzene, indicating a much slower reaction (Table 1 ). It should be noted that no reaction was detected in neat water. Ranieri et al. ${ }^{27}$ observed that $k_{2}$ values for this reaction depend strongly on the Kamlet-Taft hydrogen-bond accepting ability $(\beta)^{29,30}$ of the reaction media. In solvents with low $\beta$ values the

Scheme 2. $S_{\mathrm{N}} 2$ Reaction of Dimethyl-4-nitrophenylsulfonium $\left(\mathrm{S}^{+}\right)$with $n$-Butylamine $\left(\mathrm{BuNH}_{2}\right)$ To Produce Methyl 4Nitrophenyl Sulfide (P) and $N$-Methylbutylammonium

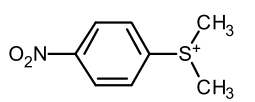

$\mathrm{S}^{+}$<smiles>CCCCNN</smiles>

$\mathrm{BuNH}_{2}$<smiles>CSc1ccc([N+](=O)[O-])cc1</smiles><smiles>CCCCNC</smiles>

$\mathrm{P}$ 
reaction tends to be faster than in solvents with high $\beta$ values. This behavior was attributed to the solvent capability to form hydrogen bonds with highly acidic methyl groups, diminishing the electrophilicity of the $\mathrm{S}^{+}$ion and reducing the reaction rate. Water has a $\beta$ value much higher than that of benzene, and the rate reaction is null in neat water and even negligible in a high $\mathrm{OH}^{-}$concentration and temperature. ${ }^{31}$ Furthermore, it is known that the amine nucleophilicity is reduced in hydrogen bond donor solvents, due to the hydrogen bond interaction between the solvent molecules and the electron pair of the amine. This interaction leads to a high degree of amine solvation and consequently reduces its availability as a nucleophile. $^{27,32,33}$ These facts explain why the reaction rate in benzene saturated with water is slower than in neat benzene. It is important to notice that, in blends such as benzene:water, water is dispersed without a defined organization/structure which leads to the formation of water microdomains (with a water molecule arrangement similar to that in bulk) where the reaction is slower than in neat benzene.

2.2. Studies in Reverse Micellar Media. Figure 2 shows the $k_{\mathrm{obs}}$ values obtained for the reaction between $\mathrm{BuNH}_{2}$ and

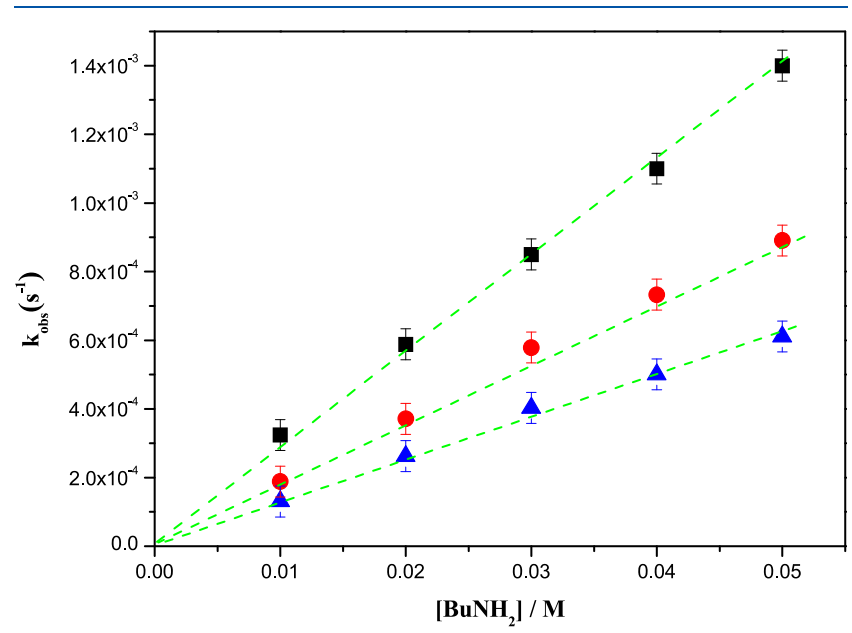

Figure 2. Dependence of $k_{\mathrm{obs}}$ values with $\mathrm{BuNH}_{2}$ concentration for the reaction between $\mathrm{S}^{+}$and $\mathrm{BuNH}_{2}$ in Na-AOT RMs at $W_{0}=0$. Straight lines were plotted to guide the eye. $[\mathrm{Na}-\mathrm{AOT}] / \mathrm{M}=$ 0.01 ; ( $0.1 ;(\boldsymbol{\Delta}) 0.2 .\left[\mathrm{S}^{+}\right]=5 \times 10^{-5} \mathrm{M} . \mathrm{T}=30^{\circ} \mathrm{C}$.

$\mathrm{S}^{+}$in benzene/Na-AOT RMs performed at different $\mathrm{BuNH}_{2}$ and Na-AOT concentrations at $W_{0}=0$. As observed, there is a linear relation between $k_{\text {obs }}$ values and $\mathrm{BuNH}_{2}$ concentration at all the Na-AOT concentrations studied. This behavior indicates that in the micellar media the reaction between $\mathrm{BuNH}_{2}$ and $\mathrm{S}^{+}$takes place under pseudo-first-order conditions.

Interestingly, Figure 2 shows that as $\mathrm{Na}$-AOT concentration increased, $k_{\text {obs }}$ values decreased considerably. For example, in $\mathrm{Na}-\mathrm{AOT} \mathrm{RMs}$ at $\left[\mathrm{BuNH}_{2}\right]=0.03 \mathrm{M}$ and $[\mathrm{Na}-\mathrm{AOT}]=0.01$ $\mathrm{M}$, the $k_{\text {obs }}$ value is $8 \times 10^{-4} \mathrm{~s}^{-1}$ while in the same RMs but at $[\mathrm{Na}-\mathrm{AOT}]=0.2 \mathrm{M}, k_{\mathrm{obs}}$ is $4 \times 10^{-4} \mathrm{~s}^{-1}$. Additionally, at the same $\left[\mathrm{BuNH}_{2}\right]$ but in neat benzene, $k_{\text {obs }}$ is $6 \times 10^{-3} \mathrm{~s}^{-1}$. As previously shown in other RMs, ${ }^{23}$ these results indicate that there is a partition process of the $\mathrm{BuNH}_{2}$ molecules between the two pseudophases (the nonpolar and RMs pseudophases). Note that, from the data shown in Figure 2, it is not possible to obtain the second-order rate constant in the RMs media, because other factors have to be taken into account. Similar effects were obtained for BHD-AOT and CTA-AOT RMs (results not shown). Hence, we decided to study the effect that the surfactant concentration (BHD-AOT, CTA-AOT, and NaAOT) has on the kinetics profiles at $W_{0}=0$ and $\left[\mathrm{BuNH}_{2}\right]=$ $0.03 \mathrm{M}$. Figure 3 shows the kinetic results $\left(k_{\mathrm{obs}}\right)$ for the BHDAOT/benzene RM system.

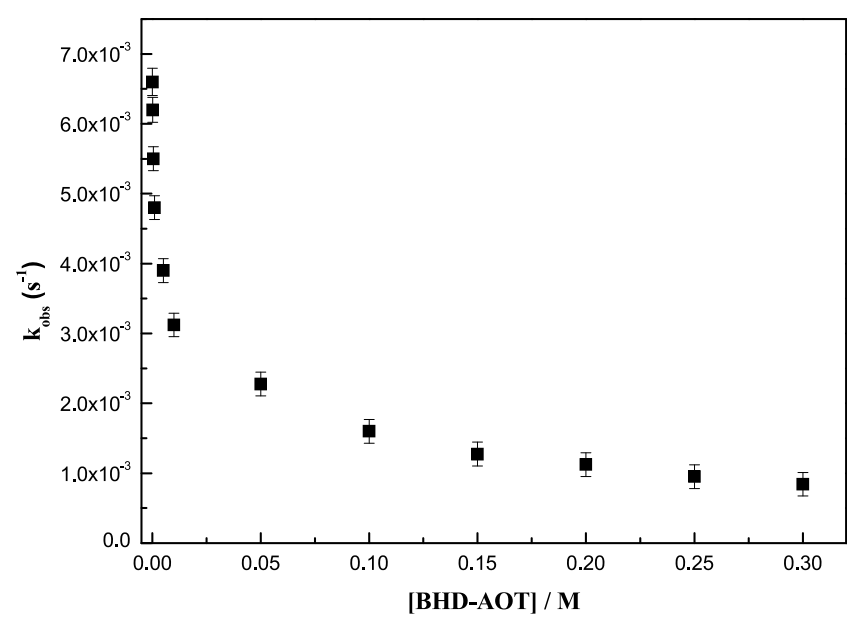

Figure 3. Dependence of $k_{\mathrm{obs}}$ values with the BHD-AOT concentration for the reaction between $\mathrm{S}^{+}$and $\mathrm{BuNH}_{2}$ in the BHDAOT/benzene RMs in the absence of water added $\left(W_{0}=0\right) .\left[\mathrm{S}^{+}\right]=5$ $\times 10^{-5} \mathrm{M} ;\left[\mathrm{BuNH}_{2}\right]=0.03 \mathrm{M} ; \mathrm{T}=30^{\circ} \mathrm{C}$.

As observed, $k_{\text {obs }}$ decreased sharply as BHD-AOT concentration is increased from 0 to $0.01 \mathrm{M}$, reaching an almost constant value after that concentration. Similar behaviors were observed for both CTA-AOT and Na-AOT RMs, as shown in Figures S3 and S4, respectively.

To explain these behaviors when varying the [surfactant], some considerations must be taken into account. Correa et al. ${ }^{34}$ studied the reaction between 4-fluoro-3-nitrobenzoate and piperidine in both BHDC and Na-AOT RMs. They observed, as in our case, that as the surfactant concentration was increased, $k_{\mathrm{obs}}$ decreased, reaching a constant value with surfactant concentrations above $0.05 \mathrm{M}$. This behavior was attributed to the partition of piperidine between the organic solvent and the micellar interface, while 4-fluoro-3-nitrobenzoate resides completely in the micellar interface.

Taking into consideration the backgrounds described above and the results shown in Figure 2, we can consider that the reaction takes place mainly in the RM pseudophase. Apparently, $\mathrm{S}^{+}$molecules are located in the micellar interior favored by the presence of the negatively charged headgroup of the AOT, an interaction that seems to anchor the molecule at the interface. On the other hand, $\mathrm{BuNH}_{2}$ molecules can be distributed between the organic phase and the micellar interface, as previously shown in Na-AOT RMs. ${ }^{35}$ In Scheme 3 is summarized the probable location of the reactants in the RMs.

As mentioned previously, the $k_{\text {obs }}$ values decreased sharply with the increment of the surfactant concentrations between 0 and 0.01 M (Figures 3, S3, and S4). These tendencies at low surfactant concentrations are typical for reactions that take place in the nonpolar/surfactant solutions but not in an organized media. To simplify our investigations, we decide to consider for the analysis only the reaction data when the RMs are formed ([surfactant] > critical micellar concentration, $\mathrm{CMC}$ ). Although, for benzene/Na-AOT RMs, the CMC value is around $10^{-3} \mathrm{M},{ }^{36}$ and for benzene/BHD-AOT and 
Scheme 3. Reaction Site in Benzene/BHD-AOT, Benzene/ CTA-AOT, and Benzene/Na-AOT RMs ${ }^{a}$

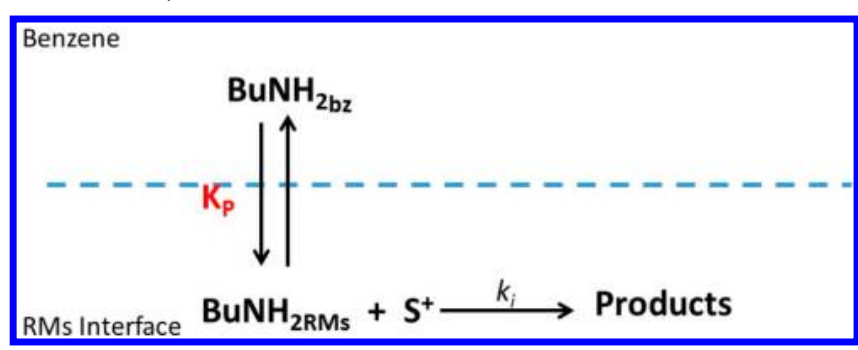

${ }^{a} \mathrm{BuNH}_{2 \mathrm{bz}}$ and $\mathrm{BuNH}_{2 \mathrm{RMs}}$ represent the $\mathrm{BuNH}_{2}$ molecules in the organic and in the RMs pseudophase, respectively.

benzene/CTA-AOT RMs, both values are around $10^{-2} \mathrm{M}$, as inferred from previous studies. ${ }^{22}$ Thus, to ensure that all $\mathrm{S}^{+}$ molecules are incorporated in the micellar interface, as proposed in Scheme 3, we worked only with [surfactant] > $0.01 \mathrm{M}$. Thus, the $\mathrm{BuNH}_{2}$ partition process can be expressed according to eq 1 :

$$
\mathrm{BuNH}_{2_{\mathrm{bz}}}+\operatorname{Surf}_{\mathrm{RMs}} \rightleftarrows \mathrm{BuNH}_{2_{\mathrm{RMs}}}
$$

where $\mathrm{BuNH}_{2 \mathrm{bz}}$ and $\mathrm{BuNH}_{2_{\mathrm{RMs}}}$ represents the $\mathrm{BuNH}_{2}$ molecules in the organic phase and the RM system, respectively. Surf $f_{\mathrm{RMs}}$ represents the surfactant that forms RMs. It is conventional for micellar aggregates to consider the concentration of micellized surfactant $\left([\text { Surf }]_{\mathrm{RMs}}\right)$ as $[\text { Surf }]_{\mathrm{RMs}}=[\text { Surf }]_{\text {Total }}-\mathrm{CMC}^{7,37}$ Also, the mass balance for $\mathrm{BuNH}_{2}$ can be considered as $\mathrm{BuNH}_{2_{\text {total }}}=\mathrm{BuNH}_{2_{\mathrm{bz}}}+\mathrm{BuNH}_{2_{\mathrm{RMs}}}$. Thus, the partition constant $\left(K_{\mathrm{p}}\right)$ of $\mathrm{BuNH}_{2}$ can be defined by eq 2 .

$$
K_{\mathrm{p}}=\frac{\left[\mathrm{BuNH}_{2}\right]_{\mathrm{RMs}}}{\left[\mathrm{BuNH}_{2}\right]_{\mathrm{bz}}[\mathrm{Surf}]_{\mathrm{RMs}}}
$$

Taking into account that in our systems only one of the reactants is partitioned between the micellar interface and the organic solvent, working in pseudo-first-order conditions it is possible to obtain the following rate equation: ${ }^{34}$

$$
k_{\mathrm{obs}}=\frac{k_{\mathrm{i}} K_{\mathrm{p}}\left[\mathrm{BuNH}_{2}\right]_{\text {total }}}{\left(1+K_{\mathrm{p}}[\text { Surf }]_{\mathrm{RMs}}\right)}
$$

where $k_{\mathrm{i}}$ is the second-order rate constant for the reaction in the RMs. $K_{\mathrm{p}}$ values were calculated by using the Encinas-Lissi method $^{38}$ (see Supporting Information), and they are shown in Table S1. These values are quite similar and expected for $\mathrm{BuNH}_{2}$ in $\mathrm{RMs}$ media. ${ }^{35}$

Using the corresponding $K_{\mathrm{p}}$ value for each RM system, $k_{\mathrm{i}}$ was calculated by fitting eq 3 at [surfactant] $>0.01 \mathrm{M}$. Figure 4 shows the fitting of data obtained in the BHD-AOT/benzene RM system at $W_{0}=0$, while in Figures S5 and S6 are plotted the data for CTA-AOT and Na-AOT RMs, respectively. All $k_{\mathrm{i}}$ values are summarized in Table 1 .

Table 1 shows that there are significant differences in the kinetic parameters of all RM systems studied. First, at $W_{0}=0$, $k_{\mathrm{i}}$ values are larger in BHD-AOT RMs than in the other two systems. We have recently reported ${ }^{22}$ that the BHD-AOT interface has low polarity and especially a lower electron donor capability environment than CTA-AOT and Na-AOT, which allows faster reaction rates. Table 1 also shows that the reaction is slightly faster in CTA-AOT RMs than in Na-AOT RMs. This behavior can be explained by considering that the presence of $\mathrm{CTA}^{+}$cation at the micellar interface (more

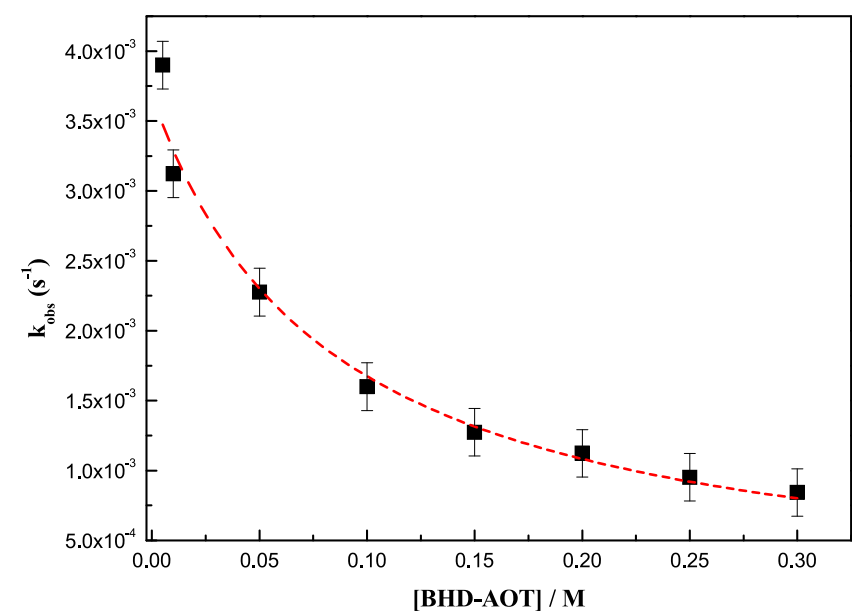

Figure 4. Plot of $k_{\mathrm{obs}}$ values as a function of [BHD-AOT] in the BHD-AOT/benzene RM system at $W_{0}=0$ analyzed (red line) according to eq 3. $\left[\mathrm{BuNH}_{2}\right]=0.03 \mathrm{M}$.

amphiphilic than $\mathrm{Na}^{+}$) reduces its electron donor capability with respect to the $\mathrm{Na}-\mathrm{AOT}$ interface; hence, the interaction with $\mathrm{S}^{+}$is diminished and the reaction rate is faster.

A similar approach was used for the RMs systems with water added $\left(W_{0}=1.5\right)$, which are shown in Figures S7, S8, and S9 for the benzene/BHD-AOT/water, benzene/CTA-AOT/ water, and benzene/Na-AOT/water RMs systems, respectively. Particularly, in the BHD-AOT system, $k_{\mathrm{i}}$ values are eight times larger than for CTA-AOT and almost 50 times larger than for Na-AOT. The water entrapped in RM systems has physicochemical properties different from that in bulk due to its interaction with the RM interface. In Na-AOT RMs, the entrapped water forms hydrogen bonds with the micellar interface, disrupting its neat structure. This interaction allows the electron pairs of water to be available to interact with $\mathrm{S}^{+}$, reducing its availability to react with $\mathrm{BuNH}_{2}$. A similar behavior can be invoked in CTA-AOT RMs; thus, the water molecules interact through hydrogen bonds with the AOT anion $^{21}$ (and also solvate the $\mathrm{S}^{+}$molecules with their free electron pairs), as represented in Scheme 4. Finally, in the BHD-AOT RMs, the water-interface interaction occurs through electron pairs of water with the BHD cation. ${ }^{22}$ This water-interface interaction is stronger than in the other two RMs studied, freeing the $\mathrm{S}^{+}$molecules and allowing faster reaction rates (Scheme 4). As suggested from previous works, ${ }^{21,22}$ in BHD-AOT RMs a stronger water-surfactant interaction can be invoked while for CTA-AOT this interaction seems to be weaker. This leads to more water molecules interacting with the interface in BHD-AOT RMs, with its hydrogen bond network completely disrupted. On the other hand, for CTA-AOT RMs a weaker water-catanionic surfactant interaction allows the water molecules to hydrogen bond with each other. We hypothesize that the benzyl group present in the $\mathrm{BHD}^{+}$moiety in $\mathrm{BHD}$-AOT has notable impact on the behavior of the catanionic interface in comparison with the interface created in CTA-AOT. As a consequence, in BHD-AOT RMs the interfacial water appears to be less electron donating than in CTA-AOT RMs.

Even though the reaction inside RMs is slower than in pure benzene (Table 1), an important catalytic-like effect is observed in the RM systems containing entrapped water in comparison with the kinetic parameters of benzene saturated by water. For example, $k_{\mathrm{i}}$ values for BHD-AOT RMs $\left(W_{0}=\right.$ 
Scheme 4. Location of $\mathrm{S}^{+}$and $\mathrm{BuNH}_{2}$ and the Effect of the Water Entrapped in (A) BHD-AOT and (B) CTA-AOT RMs

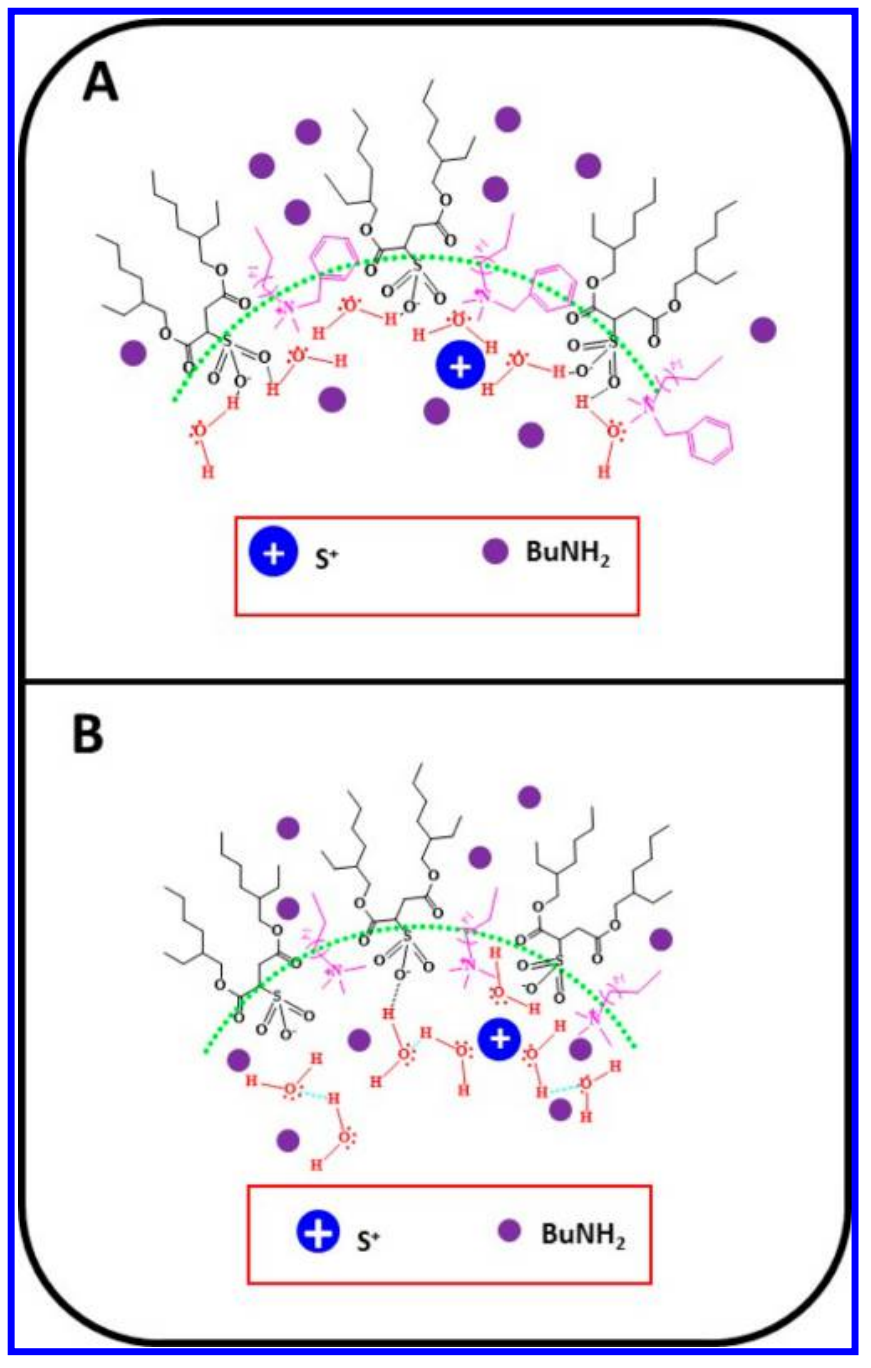

1.5) are four-fold larger than the $k_{2}$ value in the benzene saturated by water (Table 1). This catalytic-like effect is even noticeable in RM systems with a high water content; for example, the $k_{\mathrm{i}}$ value for $\mathrm{Na}$-AOT RMs at $W_{0}=10$ is still larger than in the benzene saturated by water. Interestingly, the data show that, in $\mathrm{RM}$ media, water does not solvate $\mathrm{BuNH}_{2}$ molecules as strong as in homogeneous media, because the rate constant values are very much larger than that observed in water and benzene:water mixtures (Table 1). It is important to notice that in all micellar media studied at $W_{0}>0$, the final water concentration was larger than in benzene:water solution $(0.03 \mathrm{M}) \cdot{ }^{28}$ For example, at $W_{0}=1.5$ and [surfactant $]=0.05$ $\mathrm{M}$, the [water] is $0.075 \mathrm{M}$. Consequently, the amount of water around $\mathrm{S}^{+}$and $\mathrm{BuNH}_{2}$ is not the key to explain the results observed in the present work. If the amount of water was the reason for the solvation of $\mathrm{S}^{+}$, the reaction rate values in all the RMs would be smaller than in homogeneous media, opposite to our results shown in Table 1 . These results demonstrate that due to interaction with the surfactant polar head, the water molecules entrapped in RM systems have different physicochemical properties and arrangement than in bulk solution. Thus, it seems that when water is entrapped inside RMs, particularly in BHD-AOT RMs, it can solvate an electrophile without deactivating it for $S_{N} 2$ reaction. This property of the RMs can be very useful for reactions where one or both reactants are soluble in a nonpolar organic solvent.

\section{CONCLUSIONS}

In this work, the effect of interfacial water entrapped in catanionic RMs composed of BHD-AOT and CTA-AOT surfactants on the kinetic parameters of the reaction between $\mathrm{S}^{+}$and $\mathrm{BuNH}_{2}$ (following an $\mathrm{S}_{\mathrm{N}} 2$ model) was explored. This $\mathrm{S}_{\mathrm{N}} 2$ reaction was chosen due to its high dependency on the electron donor capacity of the environment. Our results show a catalytic-like effect in both RMs investigated in comparison with the reaction in benzene:water solution. Thus, when the polar solvent is entrapped in both catanionic RMs, the novel interface changes the water electron donor ability. On the other hand, we observed the difference in the kinetic parameters obtained for both catanionic RMs, with faster reactions in the BHD-AOT than in the CTA-AOT RMs. This behavior can be attributed to the strong interaction between the entrapped water and the BHD-AOT interface, which is hydrogen bonding with the AOT anion and ion-dipole interaction with the $\mathrm{BHD}^{+}$cation. The last interaction notably reduces the electron donor capacity of the interfacial water for the solvation of $\mathrm{S}^{+}$, thus accelerating the reaction. In the CTAAOT case, water interacts with the RM interface only through hydrogen bonding with the AOT anion, allowing the electron pairs of the water molecules to interact with the $\mathrm{S}^{+}$molecules, slowing the reaction. The catalytic-like effect of water entrapped in the RMs, particularly for BHD-AOT, has potential application for nanoreactors.

\section{EXPERIMENTAL SECTION}

4.1. Materials. Both catanionic surfactants, benzyl- $n$-hexadecyldimethylammonium 1,4-bis(2-ethylhexyl) sulfosuccinate (BHD-AOT) and cetyltrimethylammonium 1,4-bis(2-ethylhexyl) sulfosuccinate (CTA-AOT), were obtained following the methodology previously reported. ${ }^{19-22}$ Sodium 1,4-bis(2-ethylhexyl) sulfosuccinate (Na$\mathrm{AOT}$ ), cetyltrimethylammonium bromide (CTAB), and benzyl- $n$ hexadecyldimethylammonium chloride (BHDC) were obtained from Sigma ( $>99 \%$ purity). All surfactants were dried under vacuum prior to use. Ultrapure water was obtained from Labonco Equipment model 90901-01. Benzene and 2-propanol from Sigma (HPLC quality) were used without prior purification. $n$-Butylamine $\left(\mathrm{BuNH}_{2}\right)$ from Riedel de Haën was distilled from sodium under a nitrogen atmosphere prior to being used. $\mathrm{K}_{3}(\mathrm{CN})_{6} \mathrm{Fe}$ from Mallinckrodt and tris(2,2-bipyridine)ruthenium(II) chloride $5 \mathrm{H}_{2} \mathrm{O}\left(\mathrm{Ru}(\mathrm{bpy})^{2+}\right)$ from Sigma were used without further purification. 4-Nitrothioanisole and methyl trifluoromethanesulfonate were purchased from Sigma and used as received.

The synthesis of dimethyl-4-nitrophenylsulfonium trifluoromethanesulfonate $\left(\mathrm{S}^{+}\right)$was carried out as reported by Ranieri et al. ${ }^{27}$ with some modifications. In brief, $3 \times 10^{-3} \mathrm{~mol}$ of methyl p-nitrobenzenesulfonate was dissolved in $5 \mathrm{~mL}$ of dichloroethane and added dropwise to an appropriate volume of methyl trifluoromethanesulfonate $(0.01 \mathrm{~mol}$ approx $)$ at $4{ }^{\circ} \mathrm{C}$. To achieve a complete reaction, the mixture was stirred for $1 \mathrm{~h}$ at $37{ }^{\circ} \mathrm{C}$. The excess of methyl trifluoromethanesulfonate and dichloroethane was removed using vacuum evaporation, and the final product was crystallized and purified using small amounts of 2-propanol. The formation of $\mathrm{S}^{+}$was confirmed using UV-vis spectroscopy, with the appearance of an absorption band at $242 \mathrm{~nm}$, in accordance with the literature. ${ }^{27}$

4.2. Methods. The stock solutions of Na-AOT, BHD-AOT, and CTA-AOT in benzene were prepared by weight and volumetric dilution. All solutions were sonicated for a few minutes until they were optically clear. Different amounts of water were added using a calibrated microsyringe. The $W_{0}\left(W_{0}=\right.$ [water $] /[$ surfactant $)$ parameter was used to express the amount of water dissolved in the 
RM solutions. RMs without the addition of water correspond to a system with $W_{0}=0$.

The binding constant $\left(K_{\mathrm{p}}\right)$ of $\mathrm{BuNH}_{2}$ to the $\mathrm{RM}$ interface was determined using the Encinas-Lissi fluorescence indirect quenching method. ${ }^{35,38}$ The effect of $\mathrm{BuNH}_{2}$ in the quenching of $\mathrm{K}_{3}(\mathrm{CN})_{6} \mathrm{Fe}$ to the fluorescence molecular probe $\mathrm{Ru}(\mathrm{bpy})^{2+}$ was studied (see Supporting Information).

4.3. Kinetic Procedure. Nucleophilic substitution reactions were followed by monitoring the UV-vis absorbance of the demethylated sulfide product (Scheme 2) using an HP 8452A spectrophotometer with a thermostated cell holder. In all experiments, the wavelength used for kinetic studies was $\lambda=342 \mathrm{~nm}$. All the experiments were carried out under pseudo-first-order conditions where the sulfonium salt concentration $\left(\left[\mathrm{S}^{+}\right]=5 \times 10^{-5} \mathrm{M}\right)$ was always smaller than the $\left[\mathrm{BuNH}_{2}\right]$. All experiments were carried out at $30.0 \pm 0.1{ }^{\circ} \mathrm{C}$. To start the kinetic run, a stock solution of $\mathrm{BuNH}_{2}$ was added into a thermostated cell containing the RM solution and $\mathrm{S}^{+}$. The concentration of $\mathrm{S}^{+}$in the RM media was kept constant at $1.5 \times$ $10^{-5} \mathrm{M}$ while the concentration of $\mathrm{BuNH}_{2}$ was varied from 0.01 to $0.05 \mathrm{M}$ as needed. Thus, all the experiments were carried out under pseudo-first-order conditions, where the sulfonium salt concentration $\left(\left[\mathrm{S}^{+}\right]=5 \times 10^{-5} \mathrm{M}\right)$ was always smaller than the $\left[\mathrm{BuNH}_{2}\right]$. The pseudo-first-order rate constant $\left(k_{\text {obs }}\right)$ was obtained by a nonlinearsquares fit of the experimental data absorbance versus time $(r>$ 0.999 ) by the first-order rate equation. The value of the absorbance at infinite reaction time was consistent with the value obtained from authentic samples of the reaction product, within 3\%. The pooled standard deviation of the kinetic data, using differently prepared samples, was less than $5 \%$. Because of solubility problems in the different media used in this study, we were forced to utilize the anion trifluoromethanesulfonate as a counterion of the cationic sulfonium. No rate differences were found previously in studies involving the different sulfonium salts in molecular solvents, ${ }^{27}$ which is consistent with the view that the cationic center itself acts as the electrophilic site for reaction.

\section{ASSOCIATED CONTENT}

\section{S Supporting Information}

The Supporting Information is available free of charge on the ACS Publications website at DOI: 10.1021/acs.joc.8b02492.

The derivation of the rate equation and the determination of partition constant $K_{\mathrm{p}}$ values (PDF)

\section{AUTHOR INFORMATION}

\section{Corresponding Authors}

*E-mail: ccvilla@uniquindio.edu.co.

*E-mail: rfalcone@exa.unrc.edu.ar.

\section{ORCID}

Cristian C. Villa: 0000-0001-6530-2569

N. Mariano Correa: 0000-0002-1728-3620

R. Dario Falcone: 0000-0002-0997-3437

\section{Notes}

The authors declare no competing financial interest.

\section{ACKNOWLEDGMENTS}

Financial support from the Consejo Nacional de Investigaciones Cientificas y Técnicas (PIP CONICET 112-20150100283), Universidad Nacional de Río Cuarto (PPI-UNRC 2016-2018), Agencia Nacional de Promoción Cientifica y Técnica (PICT 2012-0232, PICT 2012-0526, PICT 20150585, and PICT-2015-2151), Vicerrectoria de Investigaciones (Universidad del Quindio), and Ministerio de Ciencia y Tecnología, gobierno de la provincia de Córdoba (PID 2013), is gratefully acknowledged. J.J.S., N.M.C., and R.D.F. hold a research position at CONICET. C.C.V. thanks CONICET for a research fellowship.

\section{REFERENCES}

(1) Correa, N. M.; Silber, J. J.; Riter, R. E.; Levinger, N. E. Nonaqueous Polar Solvents in Reverse Micelle Systems. Chem. Rev. 2012, 112 (8), 4569-4602.

(2) De, T. K.; Maitra, A. Solution behaviour of Aerosol OT in nonpolar solvents. Adv. Colloid Interface Sci. 1995, 59, 95-193.

(3) Durantini, A. M.; Falcone, R. D.; Silber, J. J.; Correa, N. M. Effect of Confinement on the Properties of Sequestered Mixed Polar Solvents: Enzymatic Catalysis in Nonaqueous 1,4-Bis-2-ethylhexylsulfosuccinate Reverse Micelles. ChemPhysChem 2016, 17 (11), $1678-1685$.

(4) Küchler, A.; Yoshimoto, M.; Luginbühl, S.; Mavelli, F.; Walde, P. Enzymatic reactions in confined environments. Nat. Nanotechnol. 2016, 11, 409.

(5) Gutierrez, J. A.; Falcone, R. D.; Lopez-Quintela, M. A.; Buceta, D.; Silber, J. J.; Correa, N. M. On the Investigation of the DropletDroplet Interactions of Sodium 1,4-Bis(2-ethylhexyl) Sulfosuccinate Reverse Micelles upon Changing the External Solvent Composition and Their Impact on Gold Nanoparticle Synthesis. Eur. I. Inorg. Chem. 2014, 2014 (12), 2095-2102.

(6) Moyano, F.; Falcone, R. D.; Mejuto, J. C.; Silber, J. J.; Correa, N. M. Cationic Reverse Micelles Create Water with Super HydrogenBond-Donor Capacity for Enzymatic Catalysis: Hydrolysis of 2Naphthyl Acetate by $\alpha$-Chymotrypsin. Chem. - Eur. J. 2010, 16 (29), 8887-8893.

(7) Blach, D.; Pessêgo, M.; Silber, J. J.; Correa, N. M.; García-Río, L.; Falcone, R. D. Ionic Liquids Entrapped in Reverse Micelles as Nanoreactors for Bimolecular Nucleophilic Substitution Reaction. Effect of the Confinement on the Chloride Ion Availability. Langmuir 2014, 30 (41), 12130-12137.

(8) Orellano, M. S.; Porporatto, C.; Silber, J. J.; Falcone, R. D.; Correa, N. M. AOT reverse micelles as versatile reaction media for chitosan nanoparticles synthesis. Carbohvdr. Polvm. 2017, 171, 8593.

(9) Yi, S.; Dai, F.; Zhao, C.; Si, Y. A reverse micelle strategy for fabricating magnetic lipase-immobilized nanoparticles with robust enzymatic activity. $S_{c i .}$ Rep. 2017, 7 (1), 9806.

(10) Blach, D.; Martínez O, F. Gold nanoparticles optical properties induced by water and an ionic liquid (bmimBF4) inside cationic reverse micelles. New I. Chem. 2017, 41 (21), 13104-13113.

(11) Tojo, C.; Buceta, D.; López-Quintela, M. A. Bimetallic nanoparticles synthesized in microemulsions: A computer simulation study on relationship between kinetics and metal segregation. I. Colloid Interface Sci. 2018, 510, 152-161.

(12) Chaurasiya, R. S.; Hebbar, H. U., Reverse Micelles for Nanoparticle Synthesis and Biomolecule Separation. In Nanoscience in Food and Agriculture 4; Ranjan, S.; Dasgupta, N.; Lichtfouse, E., Eds.; Springer International Publishing: Cham, 2017; pp 181-211.

(13) Odella, E.; Falcone, R. D.; Silber, J. J.; Correa, N. M. Nanoscale Control Over Interfacial Properties in Mixed Reverse Micelles Formulated by Using Sodium 1,4-bis-2-ethylhexylsulfosuccinate and Tri-n-octyl Phosphine Oxide Surfactants. ChemPhysChem 2016, 17 (15), 2407-2414.

(14) Hande, V. R.; Chakrabarty, S. Exploration of the presence of bulk-like water in AOT reverse micelles and water-in-oil nanodroplets: the role of charged interfaces, confinement size and properties of water. Phvs. Chem. Chem. Phys. 2016, 18 (31), 21767-21779.

(15) Agazzi, F. M.; Falcone, R. D.; Silber, J. J.; Correa, N. M. Nonaqueous reverse micelles created with a cationic surfactant: Encapsulating ethylene glycol in BHDC/non-polar solvent blends. Colloids Surf. A 2016, 509, 467-473.

(16) Quintana, S. S.; Dario Falcone, R.; Silber, J. J.; Moyano, F.; Mariano Correa, N. On the characterization of NaDEHP/n-heptane nonaqueous reverse micelles: the effect of the polar solvent. Phvs. Chem. Chem. Phys. 2015, 17 (10), 7002-7011. 
(17) Girardi, V. R.; Silber, J. J.; Mariano Correa, N.; Darío Falcone, $\mathrm{R}$. The use of two non-toxic lipophilic oils to generate environmentally friendly anionic reverse micelles without cosurfactant. Comparison with the behavior found for traditional organic nonpolar solvents. Colloids Surf., A 2014, 457, 354-362.

(18) Agazzi, F. M.; Rodriguez, J.; Falcone, R. D.; Silber, J. J.; Correa, N. M. PRODAN Dual Emission Feature To Monitor BHDC Interfacial Properties Changes with the External Organic Solvent Composition. Langmuir 2013, 29 (11), 3556-3566.

(19) Villa, C. C.; Correa, N. M.; Silber, J. J.; Moyano, F.; Falcone, R. D. Singularities in the physicochemical properties of spontaneous AOT-BHD unilamellar vesicles in comparison with DOPC vesicles. Phys. Chem. Chem. Phys. 2015, 17 (26), 17112-17121.

(20) Villa, C. C.; Moyano, F.; Ceolin, M.; Silber, J. J.; Falcone, R. D.; Correa, N. M. A Unique Ionic Liquid with Amphiphilic Properties That Can Form Reverse Micelles and Spontaneous Unilamellar Vesicles. Chem. - Eur. J. 2012, 18 (49), 15598-15601.

(21) Villa, C. C.; Silber, J. J.; Correa, N. M.; Falcone, R. D. Effect of the Cationic Surfactant Moiety on the Structure of Water Entrapped in Two Catanionic Reverse Micelles Created from Ionic Liquid-Like Surfactants. ChemPhysChem 2014, 15 (14), 3097-3109.

(22) Villa, C. C.; Silber, J. J.; Falcone, R. D.; Correa, N. M. Subtleties of catanionic surfactant reverse micelle assemblies revealed by a fluorescent molecular probe. Methods Appl. Fluoresc. 2017, 5 (4), 044001.

(23) Crosio, M. A.; Correa, N. M.; Silber, J. J.; Falcone, R. D. A protic ionic liquid, when entrapped in cationic reverse micelles, can be used as a suitable solvent for a bimolecular nucleophilic substitution reaction. Org. Biomol. Chem. 2016, 14 (11), 3170-3177.

(24) Wan, J.; Guo, J.; Miao, Z.; Guo, X. Reverse micellar extraction of bromelain from pineapple peel - Effect of surfactant structure. Food Chem. 2016, 197, 450-456.

(25) Feng, Y.; Li, Q.; Kang, G.; Ji, G.; Tang, Y.; Tu, J. Aqueous twophase/reverse micelle continuous process for recycling and simultaneous purification of polar ionic liquid from enzymatic hydrolysate. $L$. Chem. Technol. Biotechnol. 2016, 91 (2), 394-399.

(26) Chen, W.; Guo, W.; Gao, F.; Chen, L.; Chen, S.; Li, D. Phospholipase A1-Catalysed Synthesis of Docosahexaenoic AcidEnriched Phosphatidylcholine in Reverse Micelles System. Appl. Biochem. Biotechnol. 2017, 182 (3), 1037-1052.

(27) Ranieri, G.; Hallett, J. P.; Welton, T. Nucleophilic Reactions at Cationic Centers in Ionic Liquids and Molecular Solvents. Ind. Eng. Chem. Res. 2008, 47 (3), 638-644.

(28) Karlsson, R. Solubility of water in benzene. I. Chem. Eng. Data 1973, 18 (3), 290-292.

(29) Kamlet, M. J.; Taft, R. W. The solvatochromic comparison method. I. The.beta.-scale of solvent hydrogen-bond acceptor (HBA) basicities. I. Am. Chem. Soc. 1976, 98 (2), 377-383.

(30) Taft, R. W.; Kamlet, M. J. The solvatochromic comparison method. 2. The.alpha.-scale of solvent hydrogen-bond donor (HBD) acidities. I. Am. Chem. Soc. 1976, 98 (10), 2886-2894.

(31) Coward, J. K.; Sweet, W. D. Kinetics and mechanism of methyl transfer from sulfonium compounds to various nucleophiles. $\underline{\text { L. Org. }}$ Chem. 1971, 36 (16), 2337-2346.

(32) Jencks, W. P.; Haber, M. T.; Herschlag, D.; Nazaretian, K. L. Decreasing reactivity with increasing nucleophile basicity. The effect of solvation on.beta.nuc for phosphoryl transfer to amines. $\underline{\text {. Am }}$. Chem. Soc. 1986, 108 (3), 479-483.

(33) McClelland, R. A.; Banait, N.; Steenken, S. Electrophilic reactions of xanthylium carbocations produced by flash photolysis of 9-xanthenols. L. Am. Chem. Soc. 1989, 111 (8), 2929-2935.

(34) Correa, N. M.; Durantini, E. N.; Silber, J. J. Characterization of different reverse micelle interfaces using the reaction of 4-fluoro-3nitrobenzoate with piperidine. I. Phys. Org. Chem. 2005, 18 (2), 121127.

(35) Zingaretti, L.; Mariano Correa, N.; Boscatto, L.; Chiacchiera, S. M.; Durantini, E. N.; Bertolotti, S. G.; Rivarola, C. R.; Silber, J. J. Distribution of amines in water/AOT/n-hexane reverse micelles: influence of the amine chemical structure. I. Colloid Interface Sci. 2005, 286 (1), 245-252.

(36) Ueda, M.; Schelly, Z. A. Reverse micelles of Aerosol-OT in benzene. 4. Investigation of the micropolarity using 1-methyl-8oxyquinolinium betaine as a probe. Langmuir 1989, 5 (4), 10051008.

(37) Bunton, C. A.; Nome, F.; Quina, F. H.; Romsted, L. S. Ion binding and reactivity at charged aqueous interfaces. Acc. Chem. Res. 1991, 24 (12), 357-364.

(38) Encinas, M. V.; Lissi, E. A. Solubilization of neutral molecules in AOT inverse micelles in n-heptane. Chem. Phys. Lett. 1986, 132 (6), 545-548. 